\title{
Recent Trends in Prostate Cancer Incidence by Age, Cancer Stage, and Grade, the United States, 2001-2007
}

\author{
Jun Li, ${ }^{1}$ Joseph A. Djenaba, ${ }^{1}$ Ashwini Soman, ${ }^{1}$ Sun Hee Rim, ${ }^{1}$ and Viraj A. Master ${ }^{2}$ \\ ${ }^{1}$ Division of Cancer Prevention and Control, National Center for Chronic Disease Prevention and Health Promotion, CDC, \\ 4770 Buford Hwy, MS K55, Atlanta, GA 30341, USA \\ ${ }^{2}$ Department of Urology and Winship Cancer Institute, School of Medicine, Emory University, 1365C Clifton Road, \\ Atlanta, GA 30322, USA
}

Correspondence should be addressed to Jun Li, ffa2@cdc.gov

Received 22 August 2012; Revised 25 October 2012; Accepted 31 October 2012

Academic Editor: J. W. Moul

Copyright () 2012 Jun Li et al. This is an open access article distributed under the Creative Commons Attribution License, which permits unrestricted use, distribution, and reproduction in any medium, provided the original work is properly cited.

Objective. To examine prostate cancer trends by demographic and tumor characteristics because a comprehensive examination of recent prostate cancer incidence rates is lacking. Patients and Methods. We described prostate cancer incidence rates and trends using the 2001-2007 National Program of Cancer Registries and Surveillance, Epidemiology, and End Results Program data (representing over $93 \%$ of US population). Because of coding changes in cancer grade, we restricted analysis to 2004-2007. We conducted descriptive and trend analyses using SEER*Stat. Results. The overall prostate cancer incidence rate was stable from 2001 to 2007; however, rates significantly increased among men aged 40-49 years (APC $=3.0$ ) and decreased among men aged 70-79 years $(\mathrm{APC}=2.3)$, and 80 years or older $(\mathrm{APC}=-4.4)$. About $42 \%$ of localized prostate cancers diagnosed from 2004 to 2007 were poorly differentiated. The incidence of poorly differentiated cancer significantly increased among localized $(\mathrm{APC}=8.0)$ and regional stage $(\mathrm{APC}=6.1$ ) prostate cancers during 2004-2007. Conclusions. The recent trend in prostate cancer incidence was stable but varied dramatically by age. Given the large proportion of poorly differentiated disease among localized prostate cancers and its increasing trend in more recent years, continued monitoring of prostate cancer incidence and trends by demographic and tumor characteristics is warranted.

\section{Introduction}

Prostate cancer is the most commonly diagnosed non-skin cancer and the second leading cause of cancer death among American men. Each year, approximately 220,000 men are diagnosed with prostate cancer and 29,000 die from it [1]. With the introduction of the prostate-specific antigen (PSA) testing in the mid-1980s, prostate cancer incidence rate increased drastically, at about $12 \%$ per year, and peaked in 1992 [2]. The rate subsequently declined, at about $10 \%$ per year for the following three years and then appeared to stabilize from 1995 to 2005 [2, 3]. In 2011, Kohler et al. reported a stable trend of prostate cancer incidence from 1998 to 2007; however, demographic and clinical factors were not examined in this study [4]. With the widespread use of the PSA test, the mean age at diagnosis dropped substantially, from 72.2 years between 1988-1989 to 67.2 years between
2004 and 2005 [5]. Studies using Surveillance, Epidemiology, and End Results Program (SEER) data have shown that the distribution of prostate cancer stage and grade has also dramatically changed, with localized and moderately differentiated tumors becoming predominant $[6,7]$.

Age at diagnosis, cancer stage, and grade are among the most important factors used to determine the prostate cancer treatment modality such as prostatectomy, radiation, or active surveillance [8]. Since most of screen-detected prostate cancers are low risk and are unlikely to cause death, medical experts have agreed that active surveillance, a way to monitor disease periodically rather than treat it immediately, has emerged as a viable treatment option for patients with low risk prostate cancer (http://consensus.nih .gov/2011/prostate.htm).

To our knowledge, a comprehensive examination of recent prostate cancer incidence rates and trends in the entire 
US population is lacking, especially by cancer stage and grade. As the US population ages and life expectancy continue to increase, it is increasingly important to understand distribution and changes in cancer pathological patterns. The purpose of the current study was threefold: first, to describe recent prostate cancer incidence rates and trends by demographic and tumor characteristics using the nationwide cancer registry data; second, to provide age-specific information on pathological patterns of prostate cancer; third, to show distributions and temporal changes of cancer grade within each cancer stage.

\section{Patients and Methods}

New cases of prostate cancer (incident cases) were collected by population-based cancer registries affiliated with the CDC's National Program of Cancer Registries (NPCR) or the National Cancer Institute's Surveillance, Epidemiology, and End Results (SEER) program using medical records as the source of information for tumor and demographic characteristics $[9,10]$. Both NPCR and SEER data were collected and reported using standard data items, uniform codes, and procedures as documented by the North American Association of Central Cancer Registries (NAACCR) [10]. We analyzed data from 46 population-based state cancer registries that met the United State Cancer Statistics (USCS) data publication standard for all years from 2001 to 2007 (http://www.cdc.gov/cancer/npcr/standards.htm). Data from Mississippi, Nevada, Tennessee, Virginia, and Washington DC were excluded because they did not meet these criteria for all study years. These 46 registries covered $93.5 \%$ of the US population. Cancer registries coded primary cancer site and histology according to criteria in the third edition of the International Classification of Diseases for Oncology (ICD-O-3) [11]. In this study, prostate cancer cases were identified by the ICD-O-3 site code C619 and behavior code 3 . We excluded 16,510 autopsy only or death certificated only cases (1.3\%) and 28,173 nonmicroscopically confirmed cases $(2.0 \%)$. Because nearly $99 \%$ of prostate cancers are adenocarcinomas, we restricted our analyses to adenocarcinoma only, which we identified by the following ICD-O-3 histology codes: 8140, 8141, 8143, 8147, 8211, $8251,8255,8260,8261,8262,8263,8310,8322,8323,8480$, 8481 , and 8550 . As a result, we excluded additional 19,037 cases $(1.2 \%)$ and the final study population was $1,310,373$ cases.

We stratified cases by age group $(<40,40-49,50-59$, $60-69,70-79$, or 80 years or above), race (white, black, Asian/Pacific Islander (API), American Indian/Alaska Native (AIAN), or unknown), Hispanic ethnicity, US Census region of residence (Northeast, Midwest, South, and West), and cancer stage and grade (see Table 1). For cancer registry purposes, we used SEER Summary staging instead of AJCC staging system in this study. Prostate cancer stage was based on SEER Summary Stage 2000 rules (http://seer.cancer .gov/tools/ssm/) for diagnosis years 2001-2003 and on Collaborative Stage rules (http://web.facs.org/cstage/schemalist .htm) for diagnosis years 2004-2007. To characterize cancer stage at diagnosis across all study years, we then combined these two staging systems and used three categories: no invasion beyond prostatic capsule (localized stage), invasion beyond prostatic capsule to adjacent organs or regional lymph nodes (regional stage), and invasion to distant organs or distant lymph nodes (distant stage). Prostate cancer grade was determined by Gleason score. Briefly, Gleason scores 2-4 were classified as well differentiated prostate cancer, 5 and 6 as moderately differentiated, and 7 and above as poorly differentiated. More information on Gleason's system can be found at http://training.seer.cancer.gov/prostate/abstractcode-stage/morphology.html. During 2001-2003, prostate cancers with a Gleason score 7 were coded in the cancer registries as moderately differentiated; however from 2004 to 2007 , these cases were coded as poorly differentiated [12]. To minimize the impact of this coding change on our estimates of incidence rates during the study period, 2001-2007, we collapsed grade categories into 2 groups: well differentiated; and moderately/poorly/undifferentiated. However, we used a standard (unclasped) cancer grade variable in the trend analysis from 2004 to 2007 (see Table 3).

We used annual population estimates as denominators to calculate incidence rates. All incidence rates were ageadjusted to the 2000 US standard population by the direct method. Annual percentage change (APC) is used to measure the changes in rates over time. We estimated APC of rates and the corresponding 95\% confidence intervals (CIs). We considered trends statistically significant if the $95 \%$ CIs surrounding the APC did not include zero. Because only 700 prostate cancer cases were less than 40 years old from 2001 to 2007, we excluded this group when we examined age-specific incidence rates and trends by cancer stage and grade (see Table 2). We used SEER*Stat version 7.0.4 (http://www.seer.cancer.gov/seerstat) to conduct all analyses.

\section{Results}

As shown in Table 1, for all age combined, there were $1,310,373$ newly diagnosed prostate cancer cases in the US from 2001 to 2007, with an age-adjusted incidence rate of 149.8 per 100,000 . Of these cases, $82.5 \%$ were white, $12.3 \%$ were black, $1.8 \%$ were API, and $0.3 \%$ were AIAN. About $97.0 \%$ were men aged 50 years or older, $81.0 \%$ were localized, and $2.0 \%$ were well differentiated (Table 1 ).

Although the overall prostate cancer incidence remained stable from 2001 to 2007, there were statistically significant increases in the rate for men aged $0-39$ years $(\mathrm{APC}=6.6$; $95 \% \mathrm{CI}=0.7,12.7)$ and men aged $40-49$ years $(\mathrm{APC}=$ $3.0 ; 95 \% \mathrm{CI}=0.6,5.5)$, respectively. Statistically significant decreases in incidence were observed for men aged 70-79 years $(\mathrm{APC}=-2.3 ; 95 \% \mathrm{CI}=-4.5,-0.1)$ and men aged 80 years and older $(\mathrm{APC}=-4.4 ; 95 \% \mathrm{CI}=-5.8,-3.0$ ), respectively. Significant declines in incidence also occurred among blacks ( $\mathrm{APC}=-2.1 ; \mathrm{CI}=-3.3,-0.9)$, AIANs $(\mathrm{APC}=-4.1 ; \mathrm{CI}=-7.3,-0.7)$, APIs $(\mathrm{APC}=-3.2 ; \mathrm{CI}=$ $-4.8,-1.6)$, Hispanics ( $\mathrm{APC}=-2.9 ; \mathrm{CI}=-4.4,-1.4)$, and men residing in the West $(\mathrm{APC}=-1.8 ; \mathrm{CI}=-3.3,-0.2)$. Incidence rates declined significantly over time for distant 
TABLE 1: Counts, incidence rates, and annual percentage changes in rates for prostate cancer by demographic and clinical characteristics, US men, 2001-2007.

\begin{tabular}{|c|c|c|c|c|c|c|c|c|}
\hline \multirow{2}{*}{ Total $^{2}$} & \multirow{2}{*}{$\begin{array}{c}\text { Count } \\
1,310,373\end{array}$} & \multirow{2}{*}{$\begin{array}{c}\% \\
100.0\end{array}$} & \multirow{2}{*}{$\frac{\text { Rate }^{1}}{149.8}$} & \multicolumn{2}{|c|}{$95 \%$ CI } & \multirow{2}{*}{$\begin{array}{r}\text { APC } \\
-1.6\end{array}$} & \multicolumn{2}{|c|}{$95 \%$ CI } \\
\hline & & & & 149.6 & 150.1 & & -3.8 & 0.7 \\
\hline \multicolumn{9}{|l|}{ Age } \\
\hline$<40$ & 700 & 0.1 & 0.1 & 0.1 & 0.2 & 6.6 & 0.7 & 12.7 \\
\hline $40-49$ & 35,648 & 2.7 & 23.9 & 23.7 & 24.2 & 3.0 & 0.6 & 5.5 \\
\hline $50-59$ & 257,120 & 19.6 & 221.0 & 220.2 & 221.9 & 0.0 & -2.4 & 2.5 \\
\hline $60-69$ & 475,625 & 36.3 & 693.7 & 691.7 & 695.6 & -0.8 & -3.3 & 1.7 \\
\hline $70-79$ & 409,460 & 31.2 & 897.3 & 894.6 & 900.1 & -2.3 & -4.5 & -0.1 \\
\hline $80+$ & 131,820 & 10.1 & 541.6 & 538.6 & 544.5 & -4.4 & -5.8 & -3.0 \\
\hline \multicolumn{9}{|l|}{ Race } \\
\hline White & $1,080,742$ & 82.5 & 141.2 & 140.9 & 141.5 & -1.9 & -4.2 & 0.4 \\
\hline Black & 161,158 & 12.3 & 218.4 & 217.3 & 219.5 & -2.1 & -3.3 & -0.9 \\
\hline AIAN & 4,329 & 0.3 & 74.0 & 71.7 & 76.4 & -4.1 & -7.3 & -0.7 \\
\hline API & 23,018 & 1.8 & 79.5 & 78.4 & 80.5 & -3.2 & -4.8 & -1.6 \\
\hline Unknown $^{3}$ & 41,126 & 3.1 & $\sim$ & $\sim$ & $\sim$ & $\sim$ & $\sim$ & $\sim$ \\
\hline \multicolumn{9}{|l|}{ Ethnicity ${ }^{4}$} \\
\hline Non-Spanish-Hispanic-Latino & $1,236,978$ & 94.4 & 152.3 & 152.0 & 152.5 & -1.4 & -3.7 & 0.9 \\
\hline Spanish-Hispanic-Latino & 73,395 & 5.6 & 120.7 & 119.8 & 121.6 & -2.9 & -4.4 & -1.4 \\
\hline \multicolumn{9}{|l|}{ Region } \\
\hline Northeast & 297,140 & 22.7 & 162.2 & 161.6 & 162.8 & -1.4 & -4.7 & 2.1 \\
\hline Midwest & 322,544 & 24.6 & 152.2 & 151.7 & 152.8 & -1.7 & -3.6 & 0.1 \\
\hline South & 412,862 & 31.5 & 143.8 & 143.4 & 144.3 & -1.3 & -3.7 & 1.2 \\
\hline West & 277,827 & 21.2 & 144.3 & 143.8 & 144.9 & -1.8 & -3.3 & -0.2 \\
\hline \multicolumn{9}{|l|}{ Stage $e^{5}$} \\
\hline Localized & $1,061,748$ & 81.0 & 121.4 & 121.1 & 121.6 & -1.0 & -3.2 & 1.3 \\
\hline Regional & 126,142 & 9.6 & 13.6 & 13.6 & 13.7 & 0.2 & -1.8 & 2.3 \\
\hline Distant & 41,342 & 3.2 & 5.0 & 4.9 & 5.0 & -3.1 & -4.4 & -1.8 \\
\hline Unstaged & 81,116 & 6.2 & 9.8 & 9.7 & 9.9 & -9.4 & -13.6 & -5.0 \\
\hline \multicolumn{9}{|l|}{ Grade } \\
\hline Well differentiated & 25,558 & 2.0 & 3.0 & 3.0 & 3.0 & -26.0 & -27.3 & -24.8 \\
\hline Moder/poor/undifferentiated & $1,233,810$ & 94.2 & 140.7 & 140.5 & 141.0 & -0.5 & -2.4 & 1.5 \\
\hline Unknown & 51,005 & 3.9 & 6.1 & 6.1 & 6.2 & -12.4 & -18.2 & -6.3 \\
\hline
\end{tabular}

AIAN: American Indian/Alaska Native, APC: annual percentage change, API: Asian/Pacific Islander, CI: confidence interval, moder/poor/undifferentiated: moderately, poorly, or undifferentiated.

${ }^{1}$ Rates are per 100,000 men and are age-adjusted to the 2000 US standard population.

${ }^{2}$ Data are from 46 population-based cancer registries that participate in the National Program of Cancer Registries (NPCR) and/or the Surveillance, Epidemiology, and End Results (SEER) Program and meet high quality data criteria. These registries cover 93.5\% US population for 2001-2007.

${ }^{3}$ Unknown race and race groups other than white, black, AIAN, and API are not listed but included in the total case count.

${ }^{4}$ Hispanic origin is not mutually exclusive from race categories (white, black, AIAN, and API).

${ }^{5}$ Sum of counts is less than total due to missing information on stage.

$\sim$ indicates that the denominator for the rate was unknown.

prostate cancer $(\mathrm{APC}=-3.1 ; \mathrm{CI}=-4.4,-1.8)$ and well differentiated prostate cancer $(\mathrm{APC}=-26.0 ; \mathrm{CI}=-27.3$, $-24.8)$, respectively, during the study years (Table 1 ).

As shown in Table 2, although the incidence of distant stage prostate cancer among men aged $40-49$ years remained stable from 2001 to 2007, we observed statistically significant increases in the incidence of localized and regional diseases by $3.4 \%$ and $3.5 \%$ per year, respectively. Incidence of moderately/poorly/undifferentiated prostate cancer significantly increased by $3.8 \%$ per year from 2001 to 2007 , accompanied by a significant decrease, $24.3 \%$ per year, among well differentiated cancer. For men aged 50-59 years, statistically significant declines in incidence occurred in both distant stage $(\mathrm{APC}=-1.7 ; \mathrm{CI}=-2.7,-0.6)$ and well differentiated prostate cancers $(\mathrm{APC}=-24.2 ; \mathrm{CI}=-27.5,-20.7)$. Likewise, significant declines were observed among men aged 60-69 years and men aged 70-79 years, respectively. For men aged 80 years or older, statistically significant declines in incidence occurred in each cancer stage and grade category. 
TABLE 2: Incidence rates and annual percentage changes in rates for prostate cancer by age, stage, and grade, US men over 40 years, $2001-$ 2007.

\begin{tabular}{|c|c|c|c|c|c|c|c|c|}
\hline \multirow{2}{*}{$40-49$ years } & \multirow[t]{2}{*}{ Count $^{1}$} & \multirow[t]{2}{*}{$\%$} & \multirow[t]{2}{*}{ Rate $^{2}$} & \multicolumn{2}{|c|}{$95 \% \mathrm{CI}$} & \multirow[t]{2}{*}{ APC } & \multicolumn{2}{|c|}{$95 \% \mathrm{CI}$} \\
\hline & & & & & & & & \\
\hline \multicolumn{9}{|l|}{ Stage $^{3}$} \\
\hline Localized & 27,959 & 78.4 & 18.8 & 18.6 & 19.0 & 3.4 & 0.9 & 5.9 \\
\hline Regional & 5,360 & 15.0 & 3.6 & 3.5 & 3.7 & 3.5 & 0.8 & 6.3 \\
\hline Distant & 1,048 & 2.9 & 0.7 & 0.7 & 0.7 & 1.5 & -1.2 & 4.3 \\
\hline Unstaged & 1,279 & 3.6 & 0.9 & 0.8 & 0.9 & -5.2 & -12.5 & 2.7 \\
\hline \multicolumn{9}{|l|}{ Grade } \\
\hline Well differentiated, grade I & 512 & 1.4 & 0.3 & 0.3 & 0.4 & -24.3 & -31.3 & -16.6 \\
\hline Moder/poor/undifferentiated & 34,161 & 95.8 & 22.9 & 22.7 & 23.2 & 3.8 & 1.7 & 5.9 \\
\hline Unknown & 975 & 2.7 & 0.7 & 0.6 & 0.7 & -6.8 & -17.5 & 5.3 \\
\hline \multicolumn{9}{|l|}{$50-59$ years } \\
\hline \multicolumn{9}{|l|}{ Stage $^{3}$} \\
\hline Localized & 205,439 & 79.9 & 176.6 & 175.8 & 177.3 & 0.3 & -2.3 & 3.1 \\
\hline Regional & 36,709 & 14.3 & 31.6 & 31.3 & 31.9 & 0.8 & -1.2 & 2.8 \\
\hline Distant & 5,542 & 2.2 & 4.8 & 4.6 & 4.9 & -1.7 & -2.7 & -0.6 \\
\hline Unstaged & 9,423 & 3.7 & 8.1 & 7.9 & 8.3 & -7.9 & -11.9 & -3.7 \\
\hline \multicolumn{9}{|l|}{ Grade } \\
\hline Well differentiated, grade I & 3,924 & 1.5 & 3.4 & 3.3 & 3.5 & -24.2 & -27.5 & -20.7 \\
\hline Moder/poor/undifferentiated & 246,555 & 95.9 & 211.9 & 211.1 & 212.8 & 0.9 & -1.3 & 3.1 \\
\hline Unknown & 6,641 & 2.6 & 5.7 & 5.6 & 5.9 & -12.9 & -21.8 & -3.1 \\
\hline \multicolumn{9}{|l|}{$60-69$ years } \\
\hline \multicolumn{9}{|l|}{ Stage $^{3}$} \\
\hline Localized & 386,583 & 81.3 & 564.1 & 562.3 & 565.9 & -0.7 & -3.3 & 2.0 \\
\hline Regional & 55,990 & 11.8 & 81.2 & 80.5 & 81.9 & 0.8 & -1.5 & 3.1 \\
\hline Distant & 10,917 & 2.3 & 15.9 & 15.6 & 16.2 & -2.0 & -3.8 & -0.1 \\
\hline Unstaged & 22,120 & 4.7 & 32.4 & 32.0 & 32.9 & -7.0 & -11.1 & -2.8 \\
\hline \multicolumn{9}{|l|}{ Grade } \\
\hline Well differentiated, grade I & 8,600 & 1.8 & 12.6 & 12.3 & 12.9 & -26.1 & -27.7 & -24.6 \\
\hline Moder/poor/undifferentiated & 452,138 & 95.1 & 659.3 & 657.4 & 661.2 & 0.1 & -2.1 & 2.4 \\
\hline Unknown & 14,887 & 3.1 & 21.8 & 21.4 & 22.1 & -12.7 & -19.7 & -5.2 \\
\hline \multicolumn{9}{|l|}{$70-79$ years } \\
\hline \multicolumn{9}{|l|}{ Stage $^{3}$} \\
\hline Localized & 342,813 & 83.7 & 751.2 & 748.7 & 753.7 & -1.7 & -3.8 & 0.4 \\
\hline Regional & 22,923 & 5.6 & 49.9 & 49.3 & 50.6 & -1.2 & -3.9 & 1.6 \\
\hline Distant & 13,226 & 3.2 & 29.1 & 28.6 & 29.6 & -3.5 & -5.5 & -1.5 \\
\hline Unstaged & 30,498 & 7.4 & 67.1 & 66.3 & 67.8 & -9.0 & -13.3 & -4.6 \\
\hline \multicolumn{9}{|l|}{ Grade } \\
\hline Well differentiated, grade I & 9,157 & 2.2 & 20.1 & 19.7 & 20.5 & -26.3 & -27.8 & -24.7 \\
\hline Moder/poor/undifferentiated & 382,224 & 93.3 & 837.5 & 834.8 & 840.2 & -1.2 & -3.1 & 0.8 \\
\hline Unknown & 18,079 & 4.4 & 39.7 & 39.1 & 40.3 & -13.4 & -18.5 & -7.9 \\
\hline \multicolumn{9}{|l|}{$80+$ years } \\
\hline \multicolumn{9}{|l|}{ Stage $\mathrm{e}^{3}$} \\
\hline Localized & 98,414 & 74.7 & 402.5 & 399.9 & 405.0 & -2.7 & -4.0 & -1.4 \\
\hline Regional & 5,080 & 3.9 & 21.0 & 20.5 & 21.6 & -4.8 & -7.3 & -2.2 \\
\hline Distant & 10,577 & 8.0 & 44.4 & 43.5 & 45.2 & -4.6 & -6.2 & -2.8 \\
\hline Unstaged & 17,748 & 13.5 & 73.7 & 72.6 & 74.8 & -13.1 & -17.9 & -8.0 \\
\hline
\end{tabular}


Table 2: Continued.

\begin{tabular}{lccccccccc}
\hline & Count $^{1}$ & $\%$ & Rate $^{2}$ & & 95\% CI & & APC & 95\% CI \\
\hline Grade & & & & & & & & & \\
Well differentiated; grade I & 3,354 & 2.5 & 13.8 & 13.3 & 14.3 & -27.0 & -28.1 & -25.8 \\
Moder/poor/undifferentiated & 118,070 & 89.6 & 484.3 & 481.5 & 487.1 & -3.1 & -4.3 & -2.0 \\
Unknown & 10,396 & 7.9 & 43.5 & 42.6 & 44.3 & -10.8 & -14.9 & -6.4 \\
\hline
\end{tabular}

APC: annual percentage change, CI: confidence interval, moder/poor/undifferentiated: moderately, poorly, or undifferentiated.

${ }^{1}$ Data are from 46 population-based cancer registries that participate in the National Program of Cancer Registries (NPCR) and/or the Surveillance, Epidemiology, and End Results (SEER) Program and meet high quality data criteria. These registries cover 93.5\% US population for 2004-2007.

${ }^{2}$ Rates are per 100,000 men and are age-adjusted to the 2000 US standard population.

${ }^{3}$ Sum of counts is less than total due to missing information on stage.

TABLE 3: Incidence rates and annual percentage changes in rates for prostate cancer by cancer stage and grade, US men, $2004-2007$.

\begin{tabular}{|c|c|c|c|c|c|c|c|c|}
\hline \multirow[b]{2}{*}{ Total $^{2}$} & \multirow{2}{*}{$\begin{array}{c}\text { Count } \\
751,565\end{array}$} & \multirow{2}{*}{$\begin{array}{c}\% \\
100.0\end{array}$} & \multirow{2}{*}{$\begin{array}{l}\text { Rate }^{1} \\
145.3\end{array}$} & \multicolumn{2}{|c|}{$95 \% \mathrm{CI}$} & \multirow{2}{*}{$\begin{array}{c}\text { APC } \\
1.9\end{array}$} & \multicolumn{2}{|c|}{$95 \% \mathrm{CI}$} \\
\hline & & & & 144.9 & 145.6 & & -3.4 & 7.5 \\
\hline \multicolumn{9}{|l|}{ Stage $e^{3}$} \\
\hline Localized & 613,170 & 81.6 & 118.7 & 118.4 & 119.0 & 2.3 & -3.2 & 8.1 \\
\hline Regional & 75,412 & 10.0 & 13.7 & 13.6 & 13.8 & 1.8 & -4.5 & 8.6 \\
\hline Distant & 23,455 & 3.1 & 4.8 & 4.7 & 4.9 & -3.2 & -8.0 & 1.8 \\
\hline Unstaged & 39,503 & 5.3 & 8.1 & 8.0 & 8.2 & -0.2 & -1.6 & 1.1 \\
\hline \multicolumn{9}{|l|}{ Grade } \\
\hline Well differentiated & 8,618 & 1.1 & 1.7 & 1.7 & 1.7 & -25.5 & -29.5 & -21.2 \\
\hline Moderately differentiated & 368,482 & 49.0 & 70.3 & 70.0 & 70.5 & -1.8 & -6.6 & 3.2 \\
\hline Poorly differentiated & 348,426 & 46.4 & 68.0 & 67.8 & 68.2 & 6.8 & 1.3 & 12.7 \\
\hline Undifferentiated, anaplastic & 3,212 & 0.4 & 0.6 & 0.6 & 0.7 & 1.0 & -7.3 & 9.9 \\
\hline Unknown & 22,827 & 3.0 & 4.7 & 4.6 & 4.7 & 1.1 & -9.3 & 12.6 \\
\hline \multicolumn{9}{|l|}{ Localized } \\
\hline Well differentiated & 7,714 & 1.3 & 1.5 & 1.5 & 1.6 & -24.5 & -26.4 & -22.5 \\
\hline Moderately differentiated & 333,625 & 54.4 & 63.7 & 63.4 & 63.9 & -1.3 & -6.1 & 3.7 \\
\hline Poorly differentiated & 259,719 & 42.4 & 51.1 & 50.9 & 51.3 & 8.0 & 2.0 & 14.3 \\
\hline Undifferentiated, anaplastic & 1,939 & 0.3 & 0.4 & 0.4 & 0.4 & 6.3 & -5.5 & 19.7 \\
\hline Unknown & 10,173 & 1.7 & 2.0 & 2.0 & 2.1 & 0.2 & -16.0 & 19.6 \\
\hline \multicolumn{9}{|l|}{ Regional } \\
\hline Well differentiated & 210 & 0.3 & 0.0 & 0.0 & 0.0 & -23.8 & -42.3 & 0.7 \\
\hline Moderately differentiated & 16,449 & 21.8 & 2.9 & 2.9 & 3.0 & -10.9 & -17.6 & -3.8 \\
\hline Poorly differentiated & 57,506 & 76.3 & 10.5 & 10.4 & 10.6 & 6.1 & 0.6 & 11.8 \\
\hline Undifferentiated, anaplastic & 656 & 0.9 & 0.1 & 0.1 & 0.1 & -6.7 & -21.4 & 10.7 \\
\hline Unknown & 591 & 0.8 & 0.1 & 0.1 & 0.1 & -6.8 & -32.1 & 28.0 \\
\hline \multicolumn{9}{|l|}{ Distant } \\
\hline Well differentiated & 95 & 0.4 & 0.0 & 0.0 & 0.0 & -13.7 & -46.2 & 38.3 \\
\hline Moderately differentiated & 1,903 & 8.1 & 0.4 & 0.4 & 0.4 & -18.6 & -28.2 & -7.8 \\
\hline Poorly differentiated & 17,376 & 74.1 & 3.5 & 3.5 & 3.6 & -1.6 & -6.6 & 3.7 \\
\hline Undifferentiated, anaplastic & 451 & 1.9 & 0.1 & 0.1 & 0.1 & -8.2 & -30.0 & 20.5 \\
\hline Unknown & 3,630 & 15.5 & 0.8 & 0.7 & 0.8 & -1.4 & -10.2 & 8.4 \\
\hline \multicolumn{9}{|l|}{ Unstaged } \\
\hline Well differentiated & 599 & 1.5 & 0.1 & 0.1 & 0.1 & -38.7 & -60.4 & -4.9 \\
\hline Moderately differentiated & 16,488 & 41.7 & 3.3 & 3.2 & 3.3 & -1.0 & -2.4 & 0.4 \\
\hline Poorly differentiated & 13,818 & 35.0 & 2.9 & 2.8 & 2.9 & 0.4 & -2.7 & 3.7 \\
\hline Undifferentiated, anaplastic & 166 & 0.4 & 0.0 & 0.0 & 0.0 & -5.0 & -35.0 & 38.8 \\
\hline Unknown & 8,432 & 21.3 & 1.8 & 1.7 & 1.8 & 3.6 & -5.4 & 13.4 \\
\hline
\end{tabular}

APC: annual percentage change, $\mathrm{CI}$ : confidence interval.

${ }^{1}$ Rates are per 100,000 men and are age-adjusted to the 2000 US standard population.

${ }^{2}$ Data are from 46 population-based cancer registries that participate in the National Program of Cancer Registries (NPCR) and/or the Surveillance, Epidemiology, and End Results (SEER) Program and meet high quality data criteria. These registries cover 93.5\% US population for 2004-2007.

${ }^{3}$ Sum of counts is less than total due to missing information on stage. 
Table 3 shows cancer incidence rates and trends by stage and grade. For all age combined, there were 751,565 cases newly diagnosed from 2004 to 2007. About $82.0 \%$ of cases were localized. Moderately differentiated and poorly differentiated prostate cancers accounted for $49.0 \%$ and $46.4 \%$ of total cases, respectively. There was a statistically significant increase in the incidence of poorly differentiated prostate cancer by $6.8 \%$ per year from 2004 to 2007, specifically with increases of $8.0 \%$ and $6.1 \%$ per year among localized and regional prostate cancers, respectively. The incidences of well differentiated cancer declined significantly by $24.5 \%$ and $23.8 \%$ per year, respectively, among localized and regional prostate cancers. The incidences of moderately differentiated cancer significantly declined from 2004 to 2007 among regional $(\mathrm{APC}=-10.9 ; \mathrm{CI}=-17.6,-3.8)$ and distant (APC $=-18.6 ; \mathrm{CI}=-28.2,-7.8)$ prostate cancers. We obtained similar results for prostate cancer incidence rates and trends by stage and grade when we restricted our analyses to men aged 50 years and above (data not shown).

\section{Discussion}

There are several findings to emphasize from this study. First, these nationwide data show that although the overall prostate cancer incidence rate was stable from 2001 to 2007, rates significantly increased among men under age 50 years and decreased among men aged 70 years or older. Second, from 2004 to 2007, more than half of localized prostate cancers were well or moderately differentiated (Gleason scores $\leq 6)$. Last, poorly differentiated prostate cancer accounted for $42 \%$ and $76 \%$ of the localized and regional cancers, respectively. The incidence of poorly differentiated prostate cancer significantly increased for both localized and regional cancers from 2004 to 2007.

Our findings that prostate cancer incidence trends differed dramatically between younger and older men are similar to a SEER study which showed that risks for being diagnosed with prostate cancer, for both blacks and whites, increased among men aged 30-49 years, but decreased among men aged 50 year and older from 2000 to 2007 [13]. It is well known that screening influences cancer incidence to some extent. The American Cancer Society recommends discussing prostate cancer screening with men who have at least a 10-year life expectancy at age 50 if they are at average risk [14]. Most major US medical organizations also recommend against prostate cancer screening among men who have a less than 10-year life expectancy [15-17]. Results form a National Health Interview Survey study showed that the prevalence of PSA screening among men aged 70 years or older was higher in 2005 than in 2000 [18]. Thus, prostate cancer screening might not account for the decreasing trend in prostate cancer incidence in this older population. Similarly, using Behavioral Risk Factor Surveillance System and NPCR/SEER data, we found discordance of prostate cancer incidence and screening among men aged 40-49 years [19]. Thus, screening alone might not explain the changes in prostate cancer incidence in certain age groups. Additional research is necessary on changes of physicians' and patients' knowledge and perspectives of prostate cancer screening, uptake of agestratified PSA threshold for a diagnostic biopsy, and changes in environmental and behavioral risk factors of prostate cancer to better understand these discrepancies.

In 2002, Stephenson examined 1973-1997 SEER data and found that, after the introduction of PSA testing, localized and regional diseases substantially increased with a dramatic decrease in distant disease [7]. We found that from 2001 to 2007 , incidence of distant stage prostate cancer declined only among men aged 50 or older, but not men aged $40-49$ years. The reason for this age-specific decline is possibly because prostate cancer screening guidelines from major medical organizations during that time recommended men at average risk have a screening test at age 50 . Our study demonstrated a dramatic decline in incidence of well differentiated cancers from 2001 to 2007 in each age group. One possible explanation for this decline is shift toward upgrading cancer using the Gleason Scoring system [6]. Recently, pathologists have tended to assign relatively high Gleason scores to biopsy specimens of prostate in order to align more closely with scores generated from reviews of the entire surgical specimen [20]. Another possible explanation is that, in 2005, the International Society of Urologic Pathologists (ISUP) and the World Health Organization recommended pathologists report all higher tertiary grade components of the cancer as part of a Gleason score [21].

Age at diagnosis, cancer stage, and grade are important factors in determining the prostate cancer treatment regimens that influence health outcomes. For instance, Lin et al. found that men aged 35-44 years with highgrade prostate cancer had worse overall survival and disease-specific survival compared with older men [22]. As shown in our study, over $80 \%$ of prostate cancer cases were localized stage. Treatment modalities for the localized prostate cancer markedly vary by cancer grade. According to the National Comprehensive Cancer Network (NCCN) guideline (http://www.nccn.com/cancer-guidelines .html\#prostate), patients with a localized, low recurrence risk cancer (stage T1-T2a, Gleason scores $\leq 6$, and PSA < $10 \mathrm{ng} / \mathrm{mL}$ ) could be managed with active surveillance or surgery or radiation alone. In particular, patients with a less than 20-year life expectancy and a very low recurrence risk prostate cancer (stage T1c), identified by needle biopsy after an elevated PSA, may be more appropriately followed without immediate intervention such as active surveillence. Our study shows that, from 2004-2007, about 56\% of localized prostate cancers (stage T1 or T2) were well or moderately differentiated (Gleason scores $\leq 6$ ). These cancers were more likely to be categorized as low recurrence risk if they were in stage T1or T2a (according to NCCN, stage $\mathrm{T} 2 \mathrm{~b}$ and $\mathrm{T} 2 \mathrm{c}$ were in intermediate risk group). Using data from the Cancer of the Prostate Strategic Urologic Research Endeavor (CaPSUPE) registry, Cooperberg et al. found that only $9 \%$ of men with localized low recurrence risk prostate cancer did not undergo immediate treatment [23]. Thus, non preferability of active surveillance among localized low recurrence risk prostate cancer patients need to be further investigated. 
Interestingly, we found that up to $43 \%$ of localized prostate cancers were poorly or undifferentiated and that the incidence of poorly differentiated cancer rose $8.0 \%$ and $6.1 \%$ per year from 2004 to 2007 for localized and regional prostate cancers, respectively. These increasing trends may be partially attributed to the acceptance and implementation of the 2005 ISUP recommendation, which called for reporting higher tertiary Gleason patterns and reporting different Gleason grades in multiple needle biopsies [21]. However, possible effects of new environmental or behavioral exposures to incur more aggressive prostate cancer cannot be completely ruled out. Continued monitoring of the pathological pattern in prostate cancer is greatly needed to better understand the increasing trend of the poorly differentiated cancer, especially with the US Preventive Service Task Force's draft recommendation against prostate cancer screening for men of all ages [24].

Using cancer registry data, covering over $93 \%$ of the US population enables our study to have broad generalizability. However, this study is subject to at least three limitations. First, because of changes in the grading system using Gleason score, we had to combine moderately and poorly differentiated, and undifferentiated tumors into one category to achieve a complete trend analysis from 2001 to 2007. Second, cancer registry collected the "best available grade." Therefore, for men elect nonsurgically therapy, the Gleason score, which was based on biopsy, may be underrated compared with men treated surgically sooner after the diagnosis. However, urological pathologist tends to assign a higher Gleason score to biopsy specimen to address this issue. Our estimates of poorly differentiated cancer $(42 \%)$ were conservative given the issue of underestimation of Gleason score. Third, we documented a substantial number of cancers that were unstaged or had an unknown grade. This problem diminished with time indicating better data quality in more recent years. Last, although NPCR and SEER data are the most geographically comprehensive data available, not all states were included in the analysis (from $84 \%$ in the South to $100 \%$ in the Northeast).

In conclusion, this study shows opposing trends of prostate cancer incidence among younger and older men. Significant decreases in well differentiated and distant stage prostate cancers might suggest effects of PSA testing in the post-PSA-era; however, prostate cancer screening alone cannot explain the changes in prostate cancer trends. Most of the localized prostate cancers were low grade, suggesting active surveillance as a possible treatment option. Given the large proportion of poorly differentiated disease among localized prostate cancers and its increasing trend in more recent years, continued monitoring of prostate cancer incidence and trends by demographic and tumor characteristics is warranted, especially with US Preventive Service Task Force's recommendation against prostate cancer screening for American men.

\section{Abbreviations}

AIAN: American Indian/Alaska Native

API: Asian/Pacific Islander
CI: $\quad$ Confidence interval

ICD-O-3: International Classification of Diseases for Oncology

NCCN: National Comprehensive Cancer Network

NPCR: National Program of Cancer Registries

PSA: Prostate-specific antigen

SEER: Surveillance, Epidemiology, and End Results.

\section{Disclaimer}

The findings and conclusions in this paper are those of the authors and do not necessarily represent the official position of the Centers for Disease Control and Prevention.

\section{Conflict of Interests}

The authors declare that they have no conflict of interests.

\section{Acknowledgments}

The authors thank Dr. Mary C. White, who works in the Division of Cancer Prevention and Control at CDC, for her constructive comments.

\section{References}

[1] U.S. Cancer Statistics Working Group, United States Cancer Statistics: 1999-2006 Incidence and Mortality Web-Based Report, U.S. Department of Health and Human Services, Centers for Disease Control and Prevention and National Cancer Institute, Atlanta, Ga, USA, 2010.

[2] J. L. Stanford, R. A. Stephenson, L. M. Coyle et al., "Prostate Cancer Trends 1973-1995, SEER Program, National Cancer Institute," NIH 99-4543, Bethesda, Md, USA, 1999.

[3] H. G. Welch and P. C. Albertsen, "Prostate cancer diagnosis and treatment after the introduction of prostate-specific antigen screening: 1986-2005," Journal of the National Cancer Institute, vol. 101, no. 19, pp. 1325-1329, 2009.

[4] B. A. Kohler, E. Ward, B. J. McCarthy et al., "Annual report to the nation on the status of cancer, 1975-2007, featuring tumors of the brain and other nervous system," Journal of the National Cancer Institute, vol. 103, no. 9, pp. 714-736, 2011.

[5] Y. H. Shao, K. Demissie, W. Shih et al., "Contemporary risk profile of prostate cancer in the United States," Journal of the National Cancer Institute, vol. 101, no. 18, pp. 1280-1283, 2009.

[6] A. B. Jani, P. A. S. Johnstone, S. L. Liauw, V. A. Master, and O. W. Brawley, "Age and grade trends in prostate cancer (19742003): a surveillance, epidemiology, and end results registry analysis," American Journal of Clinical Oncology, vol. 31, no. 4, pp. 375-378, 2008.

[7] R. A. Stephenson, "Prostate cancer trends in the era of prostate-specific antigen an update of incidence, mortality, and clinical factors from the SEER database," Urologic Clinics of North America, vol. 29, no. 1, pp. 173-181, 2002.

[8] A. B. Jani and S. Hellman, "Early prostate cancer: clinical decision-making," The Lancet, vol. 361, no. 9362, pp. 10451053, 2003.

[9] B. F. Hankey, L. A. Ries, and B. K. Edwards, "The surveillance, epidemiology, and end results program: a national resource," 
Cancer Epidemiology Biomarkers and Prevention, vol. 8, no. 12, pp. 1117-1121, 1999.

[10] P. A. Wingo, P. M. Jamison, R. A. Hiatt et al., "Building the infrastructure for nationwide cancer surveillance and control-a comparison between The National Program of Cancer Registries (NPCR) and The Surveillance, Epidemiology, and End Results (SEER) Program (United States)," Cancer Causes and Control, vol. 14, no. 2, pp. 175-193, 2003.

[11] A. Fritz, C. Percy, A. Jack et al., International Classification of Disease for Oncology, World Health Organization, Geneva, Switzerland, 2000.

[12] C. H. Johnson, Ed., "SEER Program Coding and Staging Manual 2004, Revision 1. National Cancer Institute," NIH 045581, Bethesda, Md, USA, 2004.

[13] R. M. Merrill and A. Sloan, "Risk-adjusted incidence rates for prostate cancer in the United States," Prostate, vol. 72, no. 2, pp. 181-185, 2012.

[14] A. M. D. Wolf, R. C. Wender, R. B. Etzioni et al., "American Cancer Society guideline for the early detection of prostate cancer: update 2010," CA Cancer Journal for Clinicians, vol. 60, no. 2, pp. 70-98, 2010.

[15] "Screening for prostate cancer. American College of Physicians," Annals of Internal Medicine, vol. 126, no. 6, pp. 480484, 1997.

[16] "Prostate-specific antigen (PSA) best practice policy. American Urological Association (AUA)," Oncology, vol. 14, pp. 267280, 2000.

[17] L. S. Lim and K. Sherin, "Screening for prostate cancer in U.S. men ACPM position statement on preventive practice," American Journal of Preventive Medicine, vol. 34, no. 2, pp. 164-170, 2008.

[18] M. W. Drazer, D. Huo, M. A. Schonberg, A. Razmaria, and S. E. Eggener, "Population-based patterns and predictors of prostate-specific antigen screening among older men in the United States," Journal of Clinical Oncology, vol. 29, no. 13, pp. 1736-1743, 2011.

[19] J. Li, R. German, J. King et al., "Recent trends in prostate cancer testing and incidence among men under age of 50," Cancer Epidemiology, vol. 36, no. 2, pp. 122-127, 2012.

[20] P. C. Albertsen, J. A. H. Hanley, G. H. Barrows et al., "Prostate cancer and the Will Rogers phenomenon," Journal of the National Cancer Institute, vol. 97, no. 17, pp. 1248-1253, 2005.

[21] J. I. Epstein, W. C. Allsbrook, M. B. Amin et al., "The 2005 International Society of Urological Pathology (ISUP) consensus conference on Gleason grading of prostatic carcinoma," American Journal of Surgical Pathology, vol. 29, no. 9, pp. 1228 1242, 2005.

[22] D. W. Lin, M. Porter, and B. Montgomery, "Treatment and survival outcomes in young men diagnosed with prostate cancer: a population-based cohort study," Cancer, vol. 115, no. 13, pp. 2863-2871, 2009.

[23] M. R. Cooperberg, J. M. Broering, and P. R. Carroll, "Time trends and local variation in primary treatment of localized prostate cancer," Journal of Clinical Oncology, vol. 28, no. 7, pp. 1117-1123, 2010.

[24] R. Chou, J. M. Croswell, T. Dana et al., "Screening for prostate cancer: a review of the evidence for the U.S. Preventive Services Task Force," Annals of Internal Medicine, vol. 155, pp. 762-771, 2011. 


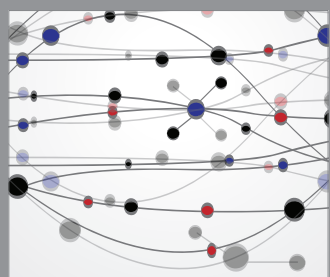

The Scientific World Journal
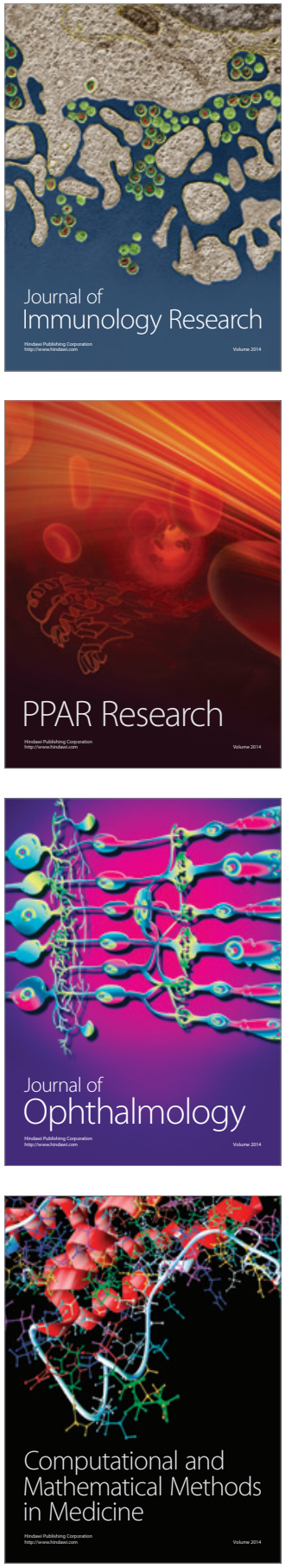

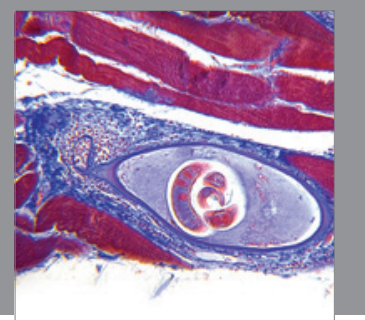

Gastroenterology

Research and Practice
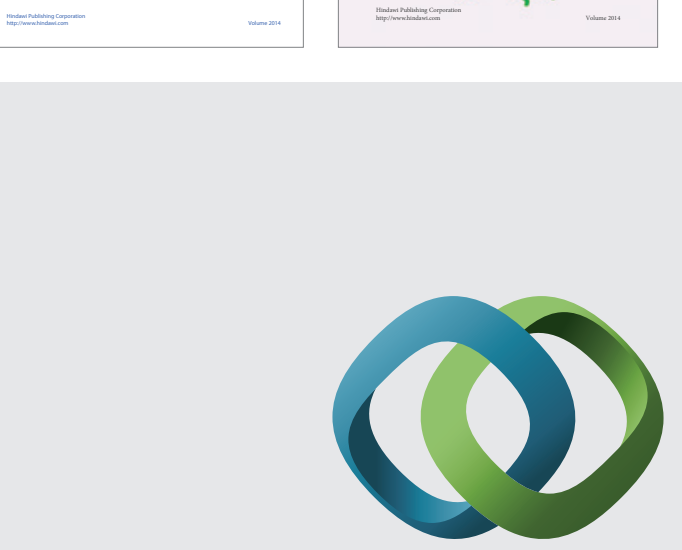

\section{Hindawi}

Submit your manuscripts at

http://www.hindawi.com
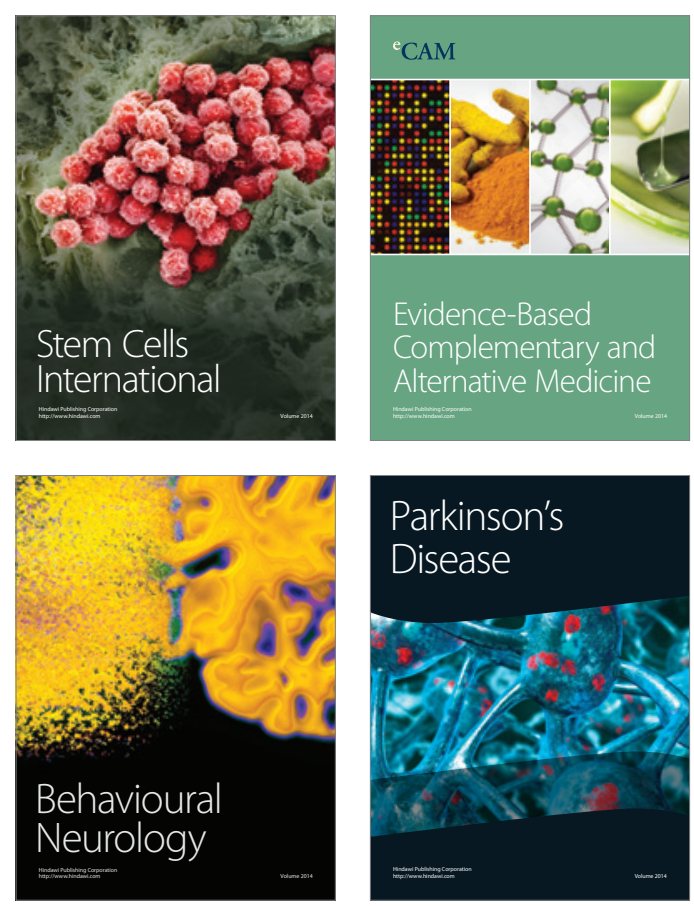

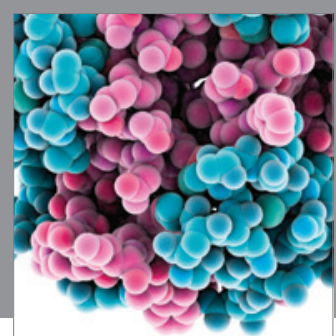

Journal of
Diabetes Research

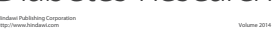

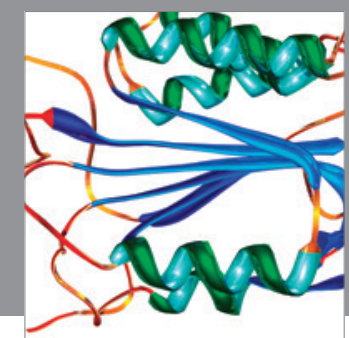

Disease Markers
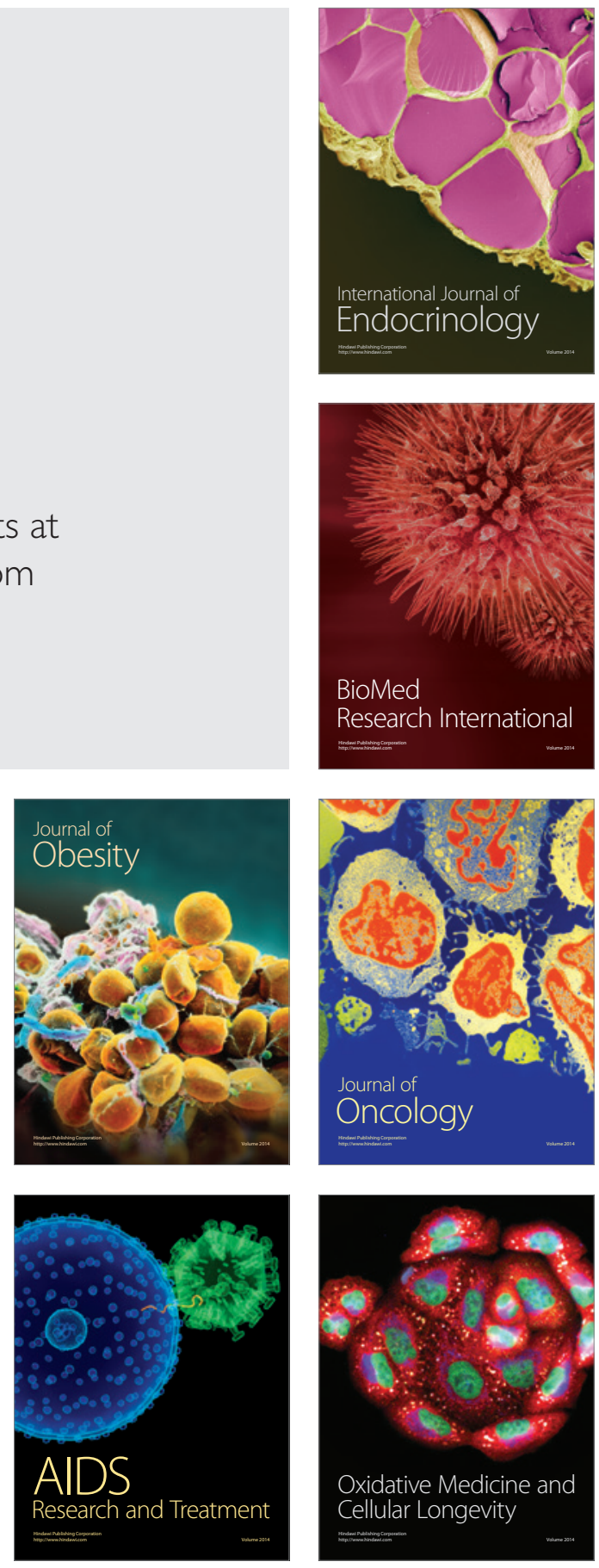